\title{
Spatial Heterogeneity and Socio-economic Correlates of Unmet Need for Spacing in India: Evidences From National Family Health Survey, 2015-16
}

Margubur Rahaman ( $\nabla$ margubur48@gmail.com )

International Institute for Population Sciences https://orcid.org/0000-0002-2707-8639

MD Juel Rana

International Institute for Population Sciences

Avijit Roy

University of Gour Banga

Pradip Chouhan

University of Gour Banga

Research

Keywords: Spacing births, contraception, unmet need, India, spatial heterogeneity

Posted Date: September 30th, 2021

DOl: https://doi.org/10.21203/rs.3.rs-882681/v1

License: (c) (1) This work is licensed under a Creative Commons Attribution 4.0 International License.

Read Full License 


\section{Abstract}

\section{Background:}

The high unmet need for contraception among women who wants to delay their subsequent births for two or more years is a challenging issue in India. Therefore, the present study aims to display spatial heterogeneity and determine the associated factors underlying the unmet need for contraception among the currently married women aged 15-49 years with a demand for spacing births in India.

\section{Methods:}

The present study used data from the National Family and Health Survey, 2015-16. Unmet need for spacing (UNS) used as outcomes and socio-cultural and demographic factors as explanatory variables. Among the comprehensive family planning, $16.7 \%$ (56742 women) of currently married women had demand for spacing births were used for analysis. Univariate, bivariate with chi-square significance test, spatial natural break technique, and multivariate logistic regression were used to accomplish the study objectives.

\section{Results:}

Almost $17 \%$ of women had demand spacing out of total demand for family planning in India. High unmet need for contraception found among them except the women with higher-level education and wealth status. District level spatial heterogeneity of UNS shows 119 districts had very high unmet for spacing (69\% and above). Results from multivariate logistic regression show that UNS's likelihood was noticeably high among the women with parity three or more (AOR: 1.42 [1.3-1.55]) compared to their counterparts. Similarly, 44\% (AOR: 1.44[1.38-1.51]) more likely found among the OBC than General caste. Rural (AOR: 1.24[1.19-1.30]) women compared to urban, women living in South (AOR: 6.19 [5.76-6.65]), Central (AOR: 1.52 [1.43-1.61]), and West (AOR: 1.80 [1.68-1.92]) region compared to those from North had higher odds of UNS.

\section{Conclusion:}

Deal with the UNS in India requires scaling up women education, client choice-based services, campaign on benefits of spacing births and available contraception, and socio-economically backward group centric policies.

\section{Background:}

Contraception is an integral part of family planning demand (FP) [1]. Demand for family planning includes the women who desire no additional births (limiting demand) and to delay their next births for at least two or more years during the survey (spacing demand) [2]. Globally, the existing demand for spacing is noticeably lower than limiting demand, especially in developing countries [1]. The demand for spacing 
is mainly concentrated among the early reproductive women (aged 15-19 years) and low parity (two or less) [3].

The high unmet need for family planning is one of the main hindrances to achieving SDG-3 goals in lower-and middle-income countries (LMICs) [2]. Unmet need for family planning (UFP) denotes "the number of currently married women or in the union who are fecund and want to either terminate or delay childbearing, but not using any contraceptive method" [4]. Similarly, the unmet need for spacing (UNS) denotes "the number of currently married women or in the union who are fecund and want to delay next births for at least two years or more, but not using any contraceptive method" [3].

The UFP decreased from $21.2 \%$ in 1990 to $16 \%$ in the developing world in 2010 [1]. Globally, UFP includes 153 million women, most of them from LMICs (138 million) in 2015. Unmet need was found almost two times higher in spacing demand compared to limiting demand among them. In India, UFP was 19\% in 2015-16 [5]. At the same time, the UNS was 51\% among the women who had demand for spacing.

UNS is significantly associated with millions of unintended births, mistimed births, neonatal mortality, pregnancy loss, induced abortions, small size births, and malnutrition $[6,7]$. The risk of maternal death, the third trimester bleeding, anaemia, and pre-eclampsia was $2.5,1.7,1.3$, and 1.8 times, respectively higher among the women who followed shorter inter-pregnancy intervals (less than two years) compared to longer inter-pregnancy intervals [6]. Similarly, the risk of small size birth and pre-time birth was found $40 \%$ higher among the women with shorter inter-pregnancy intervals than longer ones [7]. By reducing the UNS, the risk of maternal and infant mortality and morbidities can be abridged in LMICs [8].

Existing pieces of literature were predominantly observed the trends, patterns, and socio-economic correlates of spacing demand, globally [3,9-11]. Primarily, spacing demand is high among young women with low parity found in LMICs [3]. A global pattern of demand for family planning shows that the spacing demand was considerably higher than limiting demand in Muslim populated countries [12]. The use of spacing contraceptive methods was higher among the Muslims because of religious beliefs and faiths suggested by many previous studies $[13,14]$. In India, spacing demand was found comparatively higher among the women in the young age group and residents of the North-east region [3].

Several previous studies also examined the association between spacing births and maternal and child mortality and morbidities in India and elsewhere. Little studies were looked over the existing demand and unmet need for spacing in LMICs $[9,15]$. Women's age, parity, level of education, wealth status, place of residence, and mass media exposure were found to be significant determinants of unmet need spacing (UNS) in Burundi. The UNS was prominent among young, illiterate, poor women [15]. Similar findings were also found in rural Burkina Faso [9].

India achieved below replacement level TFR except for few states and socio-economic groups in 2015-16 [5]. This achievement occurred mainly due to continuous focus on limiting family planning, promotion of incentives based on male and female sterilization, and socio-economic development $[16,17]$. However, the prime focus on family planning for limiting births has been lessening the attention on "demand, 
unmet need and using contraceptive dynamics for spacing births". National Family Health Survey (NFHS) in 2015-16, suggested that the unmet need for contraception was almost three times higher among the women who desired to spacing births than limiting births in India [5]. Still, studies have paid limited attention to understanding the factors influencing the unmet need for spacing. The only available study focuses on patterns of demand for spacing [3] and unmet need for family planning [10] rather than on the unmet need for spacing itself [18]. With this backdrop, this study seeks to fill this research gap by examining district-level spatial patterns of unmet need for spacing (UNS) and its socio-economic determinants in India. Findings are anticipated to guide policymakers concerned in designing programs and policies to reduce UNS to lessen maternal and child mortality and malnutrition.

\section{Methods:}

\section{Data Source:}

The fourth round of the National Family Health Survey (NFHS), an Indian version of the Demographic and Health Survey (DHS) carried out during 2015-16, was used in this study. The survey's main objectives are to provide reliable and detailed information on fertility and family planning, maternal and child health, nutritional status of children, utilization of maternal and child health care services, and women's autonomy. The details of the sampling design process and sample size estimation procedure are provided elsewhere [5].

The NFHS collected data using different interview schedules i.e. household schedule, eligible women/individuals, and men schedule. The present study utilized the data from women's schedule. Women's schedule was collected information from a total weightage sample of 511377 of currently married women in India [5]. The present analysis was based on the weightage sample of 56,742 of currently married aged 15-49 years and fecund women, those who had demand for spacing. The details of the sampling weights are given in the NFHS reports [5]. The correspondent data file was downloaded from the International Institute for Population Sciences (IIPS) website.

\section{Outcome variable:}

Unmet need for spacing (UNS) is considered as an outcome variable in the present study. Bradley et al. (2012) revised definition of unmet need for spacing was used to define the outcome variable [19]. The denominator for the calculation of UNS is the total currently married women (aged 15-49 years); those who desired to delay their next childbirths at least for two or more years during the survey. The numerator includes all the women whose pregnancy was mistimed; amenorrhoeic women whose last birth was mistimed; and fecund women who were neither pregnant nor amenorrhoeic, who were not using any contraception, and say they want to wait two or more years for their next births.

\section{Predictor variables:}

A range of socio-economic and demographic variables were used in the analyses that have been documented to be significantly associated with the unmet need for family planning in India and 
elsewhere in the available published literature $[16,17]$. These variables are respondent's age $(15-19,20-$ 24, 25-29 and 30 + years), parity ( $0,1,2,3+$ children), have at least one son child (yes, no), level of education (illiterate, primary, secondary and higher education), household wealth index (poorest, poorer, middle, richer and richest), religion (Hindu, Muslim and others) and caste (General, Other Backward Class [OBC], Scheduled Caste and Scheduled Tribes [SC/ST]), listening family planning massage thorough TV/radio/newspaper or mass media exposure (yes, no), place of residence (urban, rural) and geographical region (North, Central, East, North-east, West and South). The division of geographical regions is based on the NFHS-4 report (IIPS and ICF, 2017).

\section{Statistical analyses:}

Univariate, bivariate, and multivariate analyses were applied in this study. Univariate analysis was used to examine the background characteristics of the study sample. Bivariate analysis with Chi-square significance test was carried out to examine the levels and patterns of unmet need for spacing (UNS) by background characteristics. The binary logistic regression analysis was performed to find out the socioeconomic correlates of UNS. The result obtained from the regression analysis was presented in the form of both unadjusted (UOR) and adjusted odds ratios (AOR) with 95\% confidence interval (Cl). The entire analysis was carried out through STATA 14.1. In binary logistic regression, the outcome variable, i.e., UNS, was dichotomized into an unmet need (coded as 1 ) and met need (coded as 0 ) as a reference category.

\section{Results:}

\section{Distribution of demand for family planning in India:}

Figure 1 shows $66.4 \%$ of women had demand for family planning out of total currently married women in India in 2015-16. Among the total demand for family planning, the spacing and limiting demand was $16.7 \%$ and $83.3 \%$, respectively. Majority of women were not using any contraception (UNS), those who had demand for spacing.

\section{Existing demand for spacing:}

Figure 2 presents the prevalence of existing demand for spacing among currently married women aged 15-49 years by background characteristics in India. The demand for spacing decreased with increasing women's age and parity. It was noticeably higher among women aged 15-19 years (87\%) or 20-24 years (57.4\%). Similarly, it was found $89 \%$ and $62.8 \%$ among the women, whose parity was zero or one respectively. Aside from women's age and parity, son preference was also influenced the spacing demand. Spacing demand was almost six times higher among women who have no son (52.3\%) than those who have at least one son (9.4\%). The spacing demand was increased with increasing women's level of education. It was four times higher among the higher educated women as compared to illiterates (33.5 vs. $8.3 \%$ ). Among the religious groups, it was somewhat high among Muslims (23.7\%) compared to their counterparts. Figure 3 displays a wide-ranging difference in spacing demand existed between the North-eastern region (33\%) and the South region (10\%). 
Figure 4 presents the district level spatial patterns of demand for spacing in India during 2015-16. The spacing demand was significantly high (ranges from 30-43\%) includes fifty districts, and very high (more than $43 \%$ ) includes 29 districts. It was considerably higher in the majority districts of the North-eastern states and some districts of Jammu and Kashmir, Bihar, and two districts of Uttar Pradesh. In comparison, it was remarkably low in the majority districts of the South Indian states and some districts of Maharashtra and Madhya Pradesh.

\section{Sample characteristics:}

Table 1 shows background characteristics of currently married women (15-49 years) who had demand for spacing in India, 2015-16. Most of the women were aged 20-24 (41.6\%), single parity (56.5\%), having no son (53.5\%), and were secondary educated (53.6\%). Almost $23 \%$ of women were belonging to the richest, followed by richer $(21 \%)$ household wealth quintile. Among the religion and caste, most women were belonging to Hindu (76.7\%) and OBC (40.9\%) in India. 
Table 1

Background characteristics of currently marriedwomen (15-49 years) thosewho had demand for spacing in India, 2015-16

\begin{tabular}{|c|c|c|}
\hline Characteristics $(n=56742)$ & $\mathrm{n}$ & Per cent \\
\hline \multicolumn{3}{|l|}{ Age group } \\
\hline $15-19$ & 5,952 & 10.5 \\
\hline $20-24$ & 23,595 & 41.6 \\
\hline $25-29$ & 18,191 & 32.1 \\
\hline $30-34$ & 6,532 & 11.5 \\
\hline $35+$ & 2,472 & 4.4 \\
\hline \multicolumn{3}{|l|}{ Parity } \\
\hline 0 & 8,958 & 15.8 \\
\hline 1 & 32,038 & 56.5 \\
\hline 2 & 10,463 & 18.4 \\
\hline $3+$ & 5,283 & 9.3 \\
\hline \multicolumn{3}{|l|}{ Have at least one son } \\
\hline Yes & 26,400 & 46.5 \\
\hline No & 30,342 & 53.5 \\
\hline \multicolumn{3}{|l|}{ Level of education } \\
\hline Illiterate & 9,109 & 16.1 \\
\hline Primary & 6,073 & 10.7 \\
\hline Secondary & 30,400 & 53.6 \\
\hline Higher & 11,159 & 19.7 \\
\hline \multicolumn{3}{|l|}{ Wealth status } \\
\hline Poorest & 9,584 & 16.9 \\
\hline Poorer & 11,152 & 19.7 \\
\hline Middle & 10,774 & 19.0 \\
\hline Richer & 11,942 & 21.0 \\
\hline Richest & 13,290 & 23.4 \\
\hline Religion & & \\
\hline
\end{tabular}




\begin{tabular}{|lll|}
\hline Characteristics $(\boldsymbol{n}=\mathbf{5 6 7 4 2})$ & $\mathbf{n}$ & Per cent \\
\hline Hindu & 43,500 & 76.7 \\
\hline Muslim & 9,826 & 17.3 \\
\hline Others & 3,416 & 6.0 \\
\hline Caste & & \\
\hline General & 17189 & 30.3 \\
\hline OBC & 23193 & 40.9 \\
\hline SC/ST & 16351 & 28.8 \\
\hline Place of residence & & \\
\hline Urban & 19,541 & 34.4 \\
\hline Rural & 37,201 & 65.6 \\
\hline Region & & \\
\hline North & 8,280 & 14.6 \\
\hline Central & 13,230 & 23.3 \\
\hline East & 16,253 & 28.6 \\
\hline North-east & 3,705 & 6.5 \\
\hline West & 7,427 & 13.1 \\
\hline South & 7,847 & 13.8 \\
\hline Mass media exposure & & \\
\hline No & 38,098 & 67.1 \\
\hline Yes & 56,742 & 100 \\
\hline Total & & \\
\hline & & \\
\hline
\end{tabular}

\section{Prevalence of unmet need for Spacing:}

Table 1 shows the unmet need for spacing (UNS) among the currently married women aged 15-49 years by background characteristic in India in 2015-16. The UNS was found considerably high among the women aged $15-19$ years $(61.8 \%)$, parity $3+(62.8 \%)$, and illiterate $(62.9 \%)$, belonged from poorest wealth quintile (64.7\%), and South region (75.7\%). The UNS was decreased with increasing women's education and wealth status. UNS's religious differentials existed slightly, ranges from $52 \%$ in Hindu to $43.1 \%$ in others. Similarly, the gap between General and OBC was also significant, ranges from $40.2-58.2 \%$, 
respectively. Nevertheless, the rural-urban gap was $10.4 \%$, in rural (54.2\%) and urban (44.6\%). Similarly, the gap in UNS also existed between the women with FP-related mass media exposure (46.8\%) and nonexposure (59.2\%). A comprehensive regional gap in UNS was found between the North-east (32.5\%) and the South $(75.7 \%)$.

\section{Spatial heterogeneity of unmet need for spacing:}

Figure 5 shows the spatial patterns of unmet need for spacing (UNS) among currently married women aged 15-49 years across the districts of India. The map depicts a definite heterogeneity and spatial disparity in the prevalence of unmet need for spacing existed across the districts. The prevalence of UNS was found very high (range: 69\% and above) among 119 districts, followed by high (range: 49\%-69\%) among 113 districts, medium (31\%-49\%) among 139 districts. Only 128 districts showed the prevalence of UNS was very low (less than 19\%), followed by low (19\%-31\%) found in 120 districts. The cluster of very high UNS is mostly found in West Bengal, Odisha, Chhattisgarh, Assam, Tripura, Arunachal Pradesh, Uttar Pradesh, Punjab, Haryana, and Rajasthan.

\section{Results from multivariate logistic regression:}

Table 2 presents that UNS is significantly associated with women's age, parity, level of education, wealth status, religion, caste, place of residence, region, and mass media exposure. The likelihood of UNS was significantly decreased with women's age, level of education, and wealth quintile. It was found 59\% (AOR: $0.41 ; \mathrm{Cl}: 0.36-0.45)$ less likely among the women aged $35+$ than women aged $15-19$ years. Women whose parity was one (AOR: 0.65 ; Cl: $0.62-0.69$ ) or two (UOR: 0.85 ; Cl: $0.80-0.90$ ) were more protected from UNS than those whose parity was zero. On the contrary, the likelihood of UNS was noticeably high among the women whose parity was three or more (UOR: 1.20; Cl: 1.12-1.28); (AOR: 1.42; Cl: 1.3-1.55) compared to their counterparts. Women with higher education (UOR: 0.48; Cl: 0.46-0.51); (AOR: 0.70; Cl: 0.65-0.76) were less exposed to UNS than illiterates. In terms of economic aspects, the richest women (UOR: 0.38 Cl: $0.36-0.40)$; (AOR: 0.41; Cl: 0.38-0.44) had a lower likelihood of UNS than the poorest. Among the religious groups, Muslim women (AOR: 0.86; Cl: 0.82-0.9) had lower odds of UNS than Hindu.

The likelihood of UNS was found 44\% (AOR: 1.44; Cl: 1.38-1.51) and 9\% (AOR: 1.09; Cl: 1.04-1.15) more likely among the OBC and SC/ST, respectively compared to General caste. Rural (AOR: 1.24; Cl: 1.191.30) women compared to urban, women living in South (AOR: 6.19; Cl: 5.76-6.65), Central (AOR: 1.52; Cl: 1.43-1.61), and West (AOR: 1.80; Cl: 1.68-1.92) region compared to those from North had higher odds of UNS. Lastly, women who had accessed FP messages through mass media were less exposed (AOR: 0.80 ; Cl: $0.77-0.84$ ) to UNS compared to their counterparts. 
Table 2

Patterns of unmet need for spacing among currently married women aged 15-49 yearsby background characteristics in India, 2015-16

\begin{tabular}{|c|c|c|c|c|}
\hline $\begin{array}{l}\text { Characteristics ( } n= \\
56742 \text { ) }\end{array}$ & $n$ & $\begin{array}{l}\text { Unmet need for } \\
\text { spacing }\end{array}$ & $\begin{array}{l}\text { Met need for } \\
\text { spacing }\end{array}$ & $\begin{array}{l}\text { Chi2 sign } \\
\text { test }\end{array}$ \\
\hline \multicolumn{5}{|l|}{ Age group } \\
\hline $15-19$ & 5,952 & 61.8 & 38.2 & \multirow[t]{5}{*}{$p<0.001$} \\
\hline $20-24$ & 23,595 & 53.5 & 46.5 & \\
\hline $25-29$ & 18,191 & 47.2 & 52.8 & \\
\hline $30-34$ & 6,532 & 43.2 & 56.8 & \\
\hline $35+$ & 2,472 & 46.8 & 53.2 & \\
\hline \multicolumn{5}{|l|}{ Parity } \\
\hline 0 & 8,958 & 58.6 & 41.5 & \multirow[t]{4}{*}{$p<0.001$} \\
\hline 1 & 32,038 & 45.6 & 54.4 & \\
\hline 2 & 10,463 & 54.6 & 45.4 & \\
\hline $3+$ & 5,283 & 62.8 & 37.2 & \\
\hline
\end{tabular}

Have at least one son

\begin{tabular}{lllll} 
Yes & 26,400 & 50.8 & 49.2 & $p<0.001$ \\
\cline { 1 - 3 } & 30,342 & 51.0 & 49 &
\end{tabular}

Level of education

$\begin{array}{lllll}\text { Illiterate } & 9,109 & 62.9 & 37.1 & p<0.001 \\ \text { Primary } & 6,073 & 53.0 & 47 & \\ \text { Secondary } & 30,400 & 49.1 & 51 & \\ \text { Higher } & 11,159 & 45.0 & 55 & 0.001 \\ \text { Wealth status } & & & & \\ \text { Poorest } & 9,584 & 64.7 & 35.3 & \\ \text { Poorer } & 11,152 & 52.7 & 47.3 & \\ \text { Middle } & 10,774 & 51.6 & 48.4 & \\ \text { Richer } & 11,942 & 48.7 & 51.3 & 59.2 \\ \text { Richest } & 13,290 & 40.9 & & \end{array}$

Religion 


\begin{tabular}{|c|c|c|c|c|}
\hline $\begin{array}{l}\text { Characteristics ( } n= \\
56742)\end{array}$ & $\mathrm{n}$ & $\begin{array}{l}\text { Unmet need for } \\
\text { spacing }\end{array}$ & $\begin{array}{l}\text { Met need for } \\
\text { spacing }\end{array}$ & $\begin{array}{l}\text { Chi2 significance } \\
\text { test }\end{array}$ \\
\hline Hindu & 43,500 & 52.0 & 48 & $p<0.001$ \\
\hline Muslim & 9,826 & 48.5 & 51.5 & \\
\hline Others & 3,416 & 43.1 & 56.9 & \\
\hline \multicolumn{5}{|l|}{ Caste } \\
\hline General & 17189 & 40.2 & 59.8 & \multirow[t]{3}{*}{$p<0.001$} \\
\hline OBC & 23193 & 58.2 & 41.8 & \\
\hline $\mathrm{SC} / \mathrm{ST}$ & 16351 & 51.8 & 48.2 & \\
\hline \multicolumn{5}{|l|}{ Place of residence } \\
\hline Urban & 19,541 & 44.6 & 55.4 & \multirow[t]{2}{*}{$p<0.001$} \\
\hline Rural & 37,201 & 54.2 & 45.8 & \\
\hline \multicolumn{5}{|l|}{ Region } \\
\hline North & 8,280 & 38.4 & 61.6 & \multirow[t]{6}{*}{$p<0.001$} \\
\hline Central & 13,230 & 55.4 & 44.6 & \\
\hline East & 16,253 & 45.9 & 54.2 & \\
\hline North-east & 3,705 & 32.5 & 67.5 & \\
\hline West & 7,427 & 50.8 & 49.2 & \\
\hline South & 7,847 & 75.7 & 24.3 & \\
\hline \multicolumn{4}{|l|}{ Mass media exposure } & \multirow[t]{3}{*}{$p<0.001$} \\
\hline No & 18,643 & 59.2 & 40.8 & \\
\hline Yes & 38,098 & 46.8 & 53.2 & \\
\hline Total & 56,742 & 50.9 & 49.1 & \\
\hline
\end{tabular}


Table 3

Likelihood estimates of unmet need for spacing among currently married women who had demand for spacing aged 15-49 years in India, 2015-16 $n=56742$

\begin{tabular}{|lll|}
\hline Variables & UOR $[95 \% \mathrm{Cl}]$ & AOR $[95 \% \mathrm{Cl}]$ \\
\hline Age group & & \\
\hline $15-19$ (reference) & 1.00 & 1.00 \\
\hline $20-24$ & $0.71^{\star \star \star}[0.67-0.75]$ & $0.76^{\star \star \star}[0.71-0.81]$ \\
$25-29$ & $0.55^{\star \star \star}[0.52-0.59]$ & $0.55^{\star \star \star}[0.51-0.59]$ \\
$30-34$ & $0.47^{\star \star \star}[0.44-0.51]$ & $0.43^{\star \star \star}[0.40-0.47]$ \\
$35+$ & $0.54^{\star \star \star}[0.49-0.60]$ & $0.41^{\star \star \star}[0.36-0.45]$
\end{tabular}

Parity

$\begin{array}{lll}0 \text { (reference) } & 1.00 & 1.00 \\ 1 & 0.59^{\star * *}[0.57-0.62] & 0.65^{\star \star *}[0.62-0.69] \\ 2 & 0.85^{\star * *}[0.80-0.90] & 0.94[0.88-1.01] \\ 3+ & 1.20^{\star * *}[1.12-1.28] & 1.42^{\star \star *}[1.3-1.55]\end{array}$

Have at least one son

Yes (reference)

1.00

1.00

No

$1.01[0.98-1.04]$

$0.97 *[0.92-0.99]$

\section{Level of education}

Illiterate (reference)

1.00

1.00

Primary

$0.66^{\star \star \star}[0.62-0.71]$

$0.73^{\star \star \star}[0.68-0.78]$

Secondary

$0.57^{\star \star \star}[0.54-0.60]$

$0.69 \star \star \star ~[0.65-0.73]$

Higher

$0.48^{\star \star \star}[0.46-0.51]$

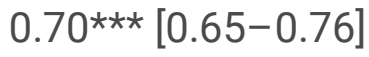

\section{Wealth status}

\begin{tabular}{|c|c|c|}
\hline Poorest (reference) & 1.00 & 1.00 \\
\hline Poorer & $0.61^{\star \star \star}[0.57-0.64]$ & $0.63^{\star \star \star}[0.6-0.67]$ \\
\hline Middle & $0.58 * \star \star[0.55-0.61]$ & $0.56 * \star \star[0.53-0.6]$ \\
\hline Richer & $0.52 * \star \star[0.49-0.55]$ & $0.49 * \star *[0.45-0.52]$ \\
\hline Richest & $0.38 * * \star[0.36-0.40]$ & $0.41 * * *[0.38-0.44]$ \\
\hline
\end{tabular}

Note: UOR = Unadjusted Odds Ratios; $\mathrm{AOR}=$ Adjusted Odds Ratios; $\mathrm{Cl}=$ Confidence Interval; ${ }^{* \star \star} \mathrm{p}<$ $0.01, p^{\star \star}<0.05, p^{\star}<0.1$ 


\begin{tabular}{|c|c|c|}
\hline Variables & UOR [95\% Cl] & AOR [95\% Cl] \\
\hline \multicolumn{3}{|l|}{ Religion } \\
\hline Hindu (reference) & 1.00 & 1.00 \\
\hline Muslim & $0.87 * \star \star[0.83-0.91]$ & $0.86^{\star * \star}[0.82-0.9]$ \\
\hline Others & $0.70 \star \star \star ~[0.65-0.75]$ & $0.91 *[0.84-0.98]$ \\
\hline \multicolumn{3}{|l|}{ Caste } \\
\hline General (reference) & 1.00 & 1.00 \\
\hline $\mathrm{OBC}$ & $2.08 * \star \star[1.99-2.16]$ & $1.44^{\star \star \star}[1.38-1.51]$ \\
\hline SC/ST & $1.60 * \star *[1.53-1.67]$ & $1.09 * \star \star[1.04-1.15]$ \\
\hline \multicolumn{3}{|l|}{ Place of residence } \\
\hline Urban (reference) & 1.00 & 1.00 \\
\hline Rural & $1.47^{\star \star \star}[1.42-1.52]$ & $1.24^{\star \star \star}[1.19-1.30]$ \\
\hline \multicolumn{3}{|l|}{ Region } \\
\hline North (reference) & 1.00 & 1.00 \\
\hline Central & $2.00 \star \star \star ~[1.89-2.11]$ & $1.52^{\star \star \star}[1.43-1.61]$ \\
\hline East & $1.36 * \star \star ~[1.29-1.44]$ & $0.91 * \star[0.85-0.96]$ \\
\hline North-east & $0.77 \star \star \star ~[0.71-0.84]$ & $0.61^{\star \star \star}[0.56-0.66]$ \\
\hline West & $1.66 * \star \star[1.56-1.77]$ & $1.80 * \star \star[1.68-1.92]$ \\
\hline South & $5.00 * \star \star[4.67-5.36]$ & $6.19 * \star \star[5.76-6.65]$ \\
\hline \multicolumn{3}{|c|}{ Mass media exposure } \\
\hline No (reference) & 1.00 & 1.00 \\
\hline Yes & $0.61^{\star \star \star}[0.58-0.63]$ & $0.80 \star \star \star ~[0.77-0.84]$ \\
\hline
\end{tabular}

\section{Discussion:}

This report found demand for spacing was significantly lower than limiting in India. Previous studies also suggested that family planning in India is highly skewed toward limiting family planning methods [20]. India will not be able to overcome the burden of child malnutrition and infant/maternal mortality without evading close birth spacing. There is a need to promote spacing family planning to minimize the burden of maternal and child malnutrition in India [21]. The spacing demand was found mainly among the 
women in the early reproductive age group (15-24 years), lower parity, had no son child in India. Previous studies also found that the spacing demand predominantly concentrated among young women and low parity [3]. The demand for spacing was found higher among the women who had not son child can be explained by son preference [22]. So that women with no son child were side-stepping to limiting their childbearing without fulfilling their desire for son child [23]. There is a need to study how many women with desired for son child were limit to their childbearing without achieving a son child in India. Among the religious groups, the spacing demand was found somewhat high among Muslims in India. In India, the religious impact on family planning is not reasonable in recent times [24]. Yet the effects of religious bigotry on acceptance of family planning and use of contraception cannot be fully denied, especially for those who are illiterate, poor and live in remote areas in India [24, 25]. A wide gap in spacing demand was observed between the South and the North-east region in India. There is a need for a study to explore the motives behind the high demand for spacing rather than limiting family planning in the North-east region.

The present study highlighted that half of the women had unmet need for spacing (UNS) in India in 201516; the result is consistent with NFHS-4 report [5]. Unmet need for spacing positively associated with risk of child and maternal health suggested by previous studies [8]. For instance, the unmet need for spacing increased the risk of unwanted and mistimed births, induced abortion and child malnutrition [6].

Therefore, the present study recommends that there is a need for family planning policy review and extensive extension of spacing family planning services. Furthermore, if the government failed to take proper strategies now, UNS will become the main reason for maternal and child health disasters in the near future. The prevalence of UNS was noticeably high found among the women aged 15-19 years, multiparous, illiterate, and belonging from poorest wealth quintile. These findings are the same as a previous study conducted in Burundi [15]. The government of India must take action soon to manage the high UNS in India. The UNS were high among illiterate women due to less knowledge about spacing contraceptive methods as documented by a previous study [26]. The wealth condition reflects the affordability and purchasing power of contraceptive methods of family planning [27]. A clear spatial heterogeneity of UNS was found across the districts in India; high UNS clusters covered most of the districts of the North-east, East and North region. There is a need to focus on spacing family planning programmes among the districts where UNS was found high.

The present study also suggested that women's age, parity, and level of education, wealth status, and religion, and caste, place of residence, region, and mass media exposure were found to be significant determinants of UNS in India. The result is consistent with the previous studies [18]. These determinants are also significantly associated with the unmet need for total family planning in India [3,26]. The likelihood of UNS has significantly deteriorated with increasing women education and wealth status. Previous studies also suggested that the use of modern contraceptives was strongly determined by the women's education level, wealth status [28]. The UNS was significantly high among the woman who resides from rural and socio-economically deprived caste (OBC, SC/ST). Socio-economic depravedness is one of the strongest factors of the unmet need for modern spacing contraception in India found in previous studies [29]. In rural India, the lack of women autonomy and knowledge about spacing contraceptive methods is positively linked with the unmet need for modern spacing contraception 
suggested by previous studies [30]. Unexpectedly, the likelihood of UNS was found higher in the regions with low TFR (South and West region) compared to their counterparts. The spacing demand was less than $15 \%$ in both regions found in the present study. Since spacing demand is low, perhaps less attention is paid to spacing family planning services, which increased the UNS in these regions. The absence of incentives for spacing births can be one of the factors for not using any contraception for spacing births in India. The district-level heterogeneity of UNS suggests there is a need to implement a district-level demand-based family planning program particularly among high UNS clusters in India. The UNS family planning continued to be low among those who had access to family planning messages through mass media, similar to the previous studies elsewhere (Nzokirishaka \& Itua, 2018). Mass media plays a positive role to increase the knowledge, acceptance and use of contraception in India proposed by existing literature in India [31]

\section{Limitations:}

This study is limited to establish causality relations between outcome and explanatory variables, nonetheless rather a mere association. Causality presumes the anteriority of explanatory variables to the outcome, which is not the case in cross-sectional data. A qualitative study is also needed to explore the concealed factors of UNS in India. This study examined the only association between women's background characteristics and UNS, and failed to draw the impact of men attitudes on UNS in the Indian male-dominated society. It is therefore important that further study explore male views and dichotomy between male and female perspectives on using contraception for spacing, a dimension that was missing in the present study. On the other hand, there is a need for further study to explore district-level KAP (knowledge, attitude and practice) of contraception for spacing births in India. It will be supportive to draw the community level challenges and opportunities of availing family planning services in sociocultural diverse India.

\section{Conclusion:}

The present study examined the socio-cultural differentials, the prevalence, and associated factors of UNS among currently married women aged 15-49 years in India in 2015-16. After controlling for other family planning associated factors, results indicate that women with UNS were primarily younger, poor and illiterate, parity 0 or $3+$, and were not exposed to mass media. Among the social groups, socioeconomically marginalised women (OBC and SC/ST) were poorly using contraception to spacing their next births. Women from the rural and south regions were poorly protected against the UNS. Mass media plays a positive role to minimize the UNS in India. Tackling the high UNS in India requires multi-level interventions such as promoting spacing contraception services, availing couple's choice-based contraception, and community level campaigns and media coverage. Women's education, empowerment, autonomy as well as socio-economic development are needed to battle against UNS in India.

\section{Abbreviations:}


FP: Family planning; LMICs: Lower-and Middle-income countries; UFP: Unmet need for family planning; UNS: Unmet need for spacing; NFHS: National Family Health Survey; DHS: Demographic and Health Survey; IIPS: International Institute for Population Sciences; OBC: Other backward class; SC/ST: Scheduled Caste and Scheduled Tribes; TFR: Total fertility rate.

\section{Declarations:}

\section{Ethics approval and consent to participate:}

This study is based on secondary data which is available in the public domain. Therefore, ethical approval is not required for conducting this study.

\section{Consent for publication:}

Not applicable

\section{Availability of data and materials:}

The dataset analysed during the current study are available in the Demographic and Health Surveys (DHS) repository, https://dhsprogram.com/data/available-datasets.cfm.

\section{Competing interests:}

The authors have no competing of interests.

\section{Funding:}

This research did not receive any specific grant from funding agencies in the public, commercial, or notfor-profit sectors.

\section{Authors' contributions:}

MR and JR conceptualized the study aims and designed the study. AR assisted with interpretation of the analysis/results and manuscript writing. PC assisted with different parts of the manuscript editing/writing and prepared final draft of the manuscript. All authors read and approved the final manuscript.

\section{Acknowledgements:}

We would like to thanks to Asian Population Association (APA) conference members for their valuable comments and suggestions on this study.

\section{References:}


1. Alkema L, Kantorova V, Menozzi C, Biddlecom A. National, regional, and global rates and trends in contraceptive prevalence and unmet need for family planning between 1990 and 2015: a systematic and comprehensive analysis. The Lancet. 2013; 381(9878):1642-52.

2. Ewerling F, Victora CG, Raj A, Coll CV, Hellwig F, Barros AJ. Demand for family planning satisfied with modern methods among sexually active women in low-and middle-income countries: who is lagging behind?. Reproductive health. 201; 15(1):1-0.

3. Jansen WH. Existing demand for birth spacing in developing countries: perspectives from household survey data. International Journal of Gynecology \& Obstetrics. 2005; 89:S50-60.

4. Fabic MS, Choi Y, Bongaarts J, Darroch JE, Ross JA, Stover J, Tsui AO, Upadhyay J, Starbird E. Meeting demand for family planning within a generation: the post-2015 agenda. The Lancet. 2015; 385(9981):1928-31.

5. IIPS, ICF. "India National Family Health Survey NFHS-4 2015-16." Mumbai: IIPS and ICF (2017).

6. Conde-Agudelo A, Belizán JM. Maternal morbidity and mortality associated with interpregnancy interval: cross sectional study. Bmj. 2000; 321(7271):1255-9.

7. Zhu BP, Rolfs RT, Nangle BE, Horan JM. Effect of the interval between pregnancies on perinatal outcomes. New England journal of medicine. 1999; 340(8):589-94.

8. Norton M. New evidence on birth spacing: promising findings for improving newborn, infant, child, and maternal health. International Journal of Gynecology and Obstetrics. 2005; 89:S1-S6.

9. Wulifan JK, Jahn A, Hien H, Ilboudo PC, Meda N, Robyn PJ, Hamadou TS, Haidara O, De Allegri M. Determinants of unmet need for family planning in rural Burkina Faso: a multilevel logistic regression analysis. BMC pregnancy and childbirth. 2017;17(1):1-11.

10. Yadav D, Dhillon P. Assessing the impact of family planning advice on unmet need and contraceptive use among currently married women in Uttar Pradesh, India. PloS one. 2015;10(3):e0118584.

11. Deitch J, Stark L. Adolescent demand for contraception and family planning services in low-and middle-income countries: A systematic review. Global public health. 2019; 14(9):1316-34.

12. Bongaarts $\mathrm{J}$. The impact of family planning programs on unmet need and demand for contraception. Studies in family planning. 2014; 45(2):247-62.

13. Srikanthan A, Reid RL. Religious and cultural influences on contraception. Journal of obstetrics and gynaecology Canada. 2008; 30(2):129-37.

14. Pinter B, Hakim M, Seidman DS, Kubba A, Kishen M, Di Carlo C. Religion and family planning. The European Journal of Contraception \& Reproductive Health Care. 201; 21(6):486-95.

15. Nzokirishaka A, Itua I. Determinants of unmet need for family planning among married women of reproductive age in Burundi: a cross-sectional study. Contraception and reproductive medicine. 2018; 3(1):1-3.

16. Verma P, Singh KK, Singh A, Srivastava U. Population control under various family planning schemes in Uttar Pradesh, India. Genus. 2019; 75(1):1-12. 
17. Gupta HK. PSF Process in India: Achieving Rapid Population Control Using Financial Incentives. Population Review. 2004; 43(1):82-6.

18. Jejeebhoy SJ, Santhya KG, Zavier AF. Demand for contraception to delay first pregnancy among young married women in India. Studies in family planning. 2014; 45(2):183-201.

19. Bradley SE, Croft TN, Fishel JD, Westoff CF. Revising unmet need for family planning. DHS analytical studies. 2012; 25(1): 3-14. https://dhsprogram.com/pubs/pdf/AS25/AS25\%5B12June2012\%5D.pdf

20. Pradhan MR, Dwivedi LK. Changes in contraceptive use and method mix in India: 1992-92 to 201516. Sexual \& Reproductive Healthcare. 2019;19:56-63.

21. Rana MJ, Gautam A, Goli S, Reja T, Nanda P, Datta N, Verma R. Planning of births and maternal, child health, and nutritional outcomes: recent evidence from India. public health. 2019; 169:14-25.

22. Ghosh S, Begum S. Influence of son preference on contraceptive method mix: Some evidences from 'Two Bengals'. Asian Population Studies. 2015; 11(3):296-311.

23. Hoq MN. Effects of Son Preference on Contraceptive Use in Bangladesh. Kesmas: Jurnal Kesehatan Masyarakat Nasional (National Public Health Journal). 2019; 14(1).

24. Quraishi SY (2019). The Population Myth: Islam, Family Planning and Politics in India. New Delhi: HarperCollins.

25. Bhagat, R. B. (2015). Transition in Hindu and Muslim Population Growth Rates: Myth and Reality. Paper presented at the National Seminar on 'Religious Demography of India: Myths and Realities' organised by Centre for Culture and Development, Vadodara, 27-28th November, 2015.

26. Rana MJ, Goli S. The road from ICPD to SDGs: Health returns of reducing the unmet need for family planning in India. Midwifery. 2021;103:103107..

27. Rana MJ, Goli S. Family planning and its association with nutritional status of women: investigation in select South Asian countries. Indian Journal of Human Development. 2017; 11(1):56-75.

28. Misra S, Goli S, Rana MJ, Gautam A, Datta N, Nanda P, Verma R. Family Welfare Expenditure, Contraceptive Use, Sources and Method-Mix in India. Sustainability. 2021; 13(17):9562.

29. Rana MJ, Cleland J, Sekher TV, Padmadas SS. Disentangling the effects of reproductive behaviours and fertility preferences on child growth in India. Population Studies. 2021; 75(1):37-50.

30. Rana MJ, Jain AK. Do Indian women receive adequate information about contraception?. Journal of biosocial science. 2020; 52(3):338-52.

31. Ghosh R, Mozumdar A, Chattopadhyay A, Acharya R. Mass media exposure and use of reversible modern contraceptives among married women in India: An analysis of the NFHS 2015-16 data. PloS one. 2021; 16(7):e0254400.

\section{Figures}




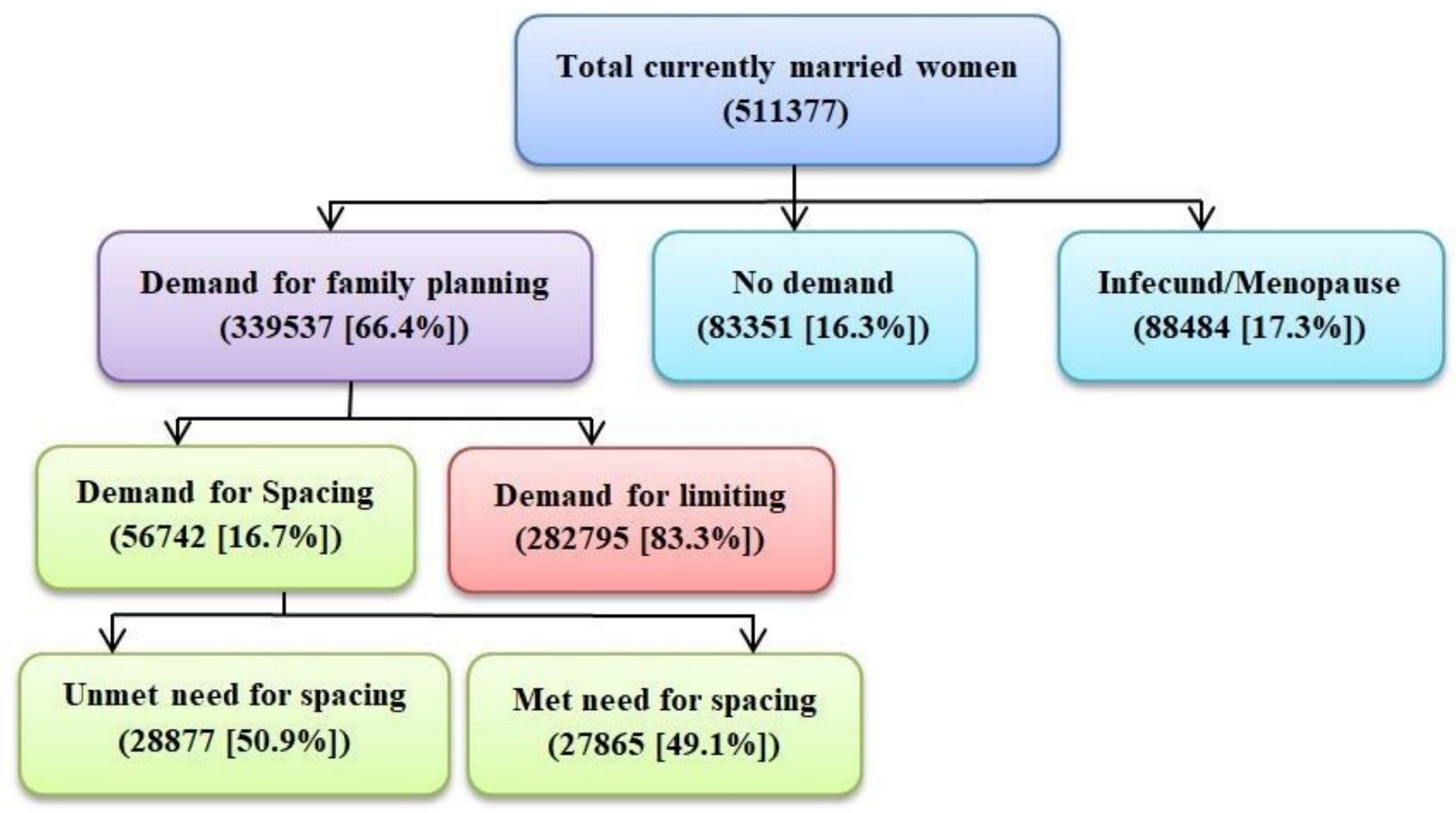

Figure 1

Graphical presentation of sample distribution, National family Health Survey 2015-16 


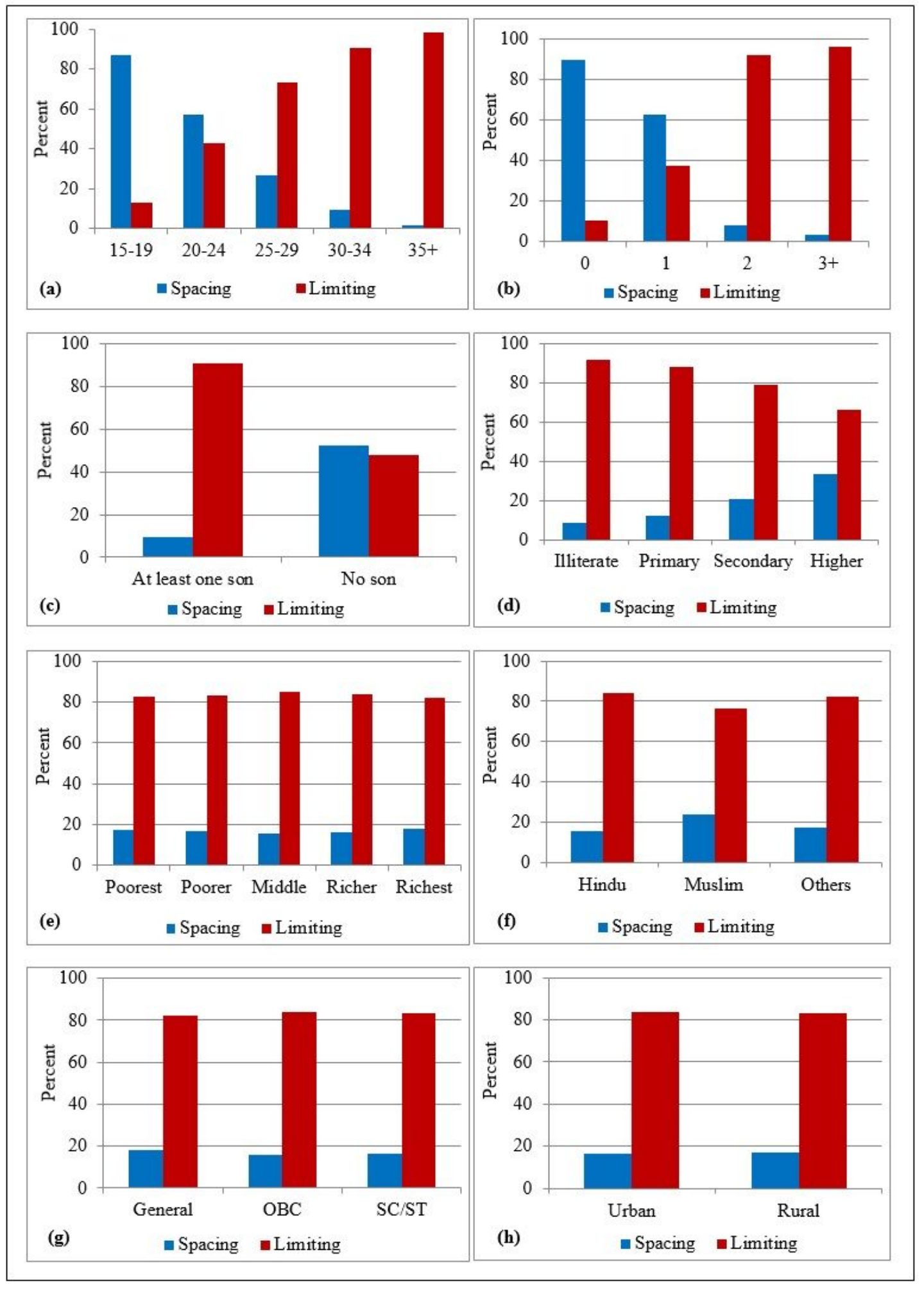

\section{Figure 2}

Existing demand for spacing among currently married women, those who had demand for family planning by (a) women's age, (b) parity, (c) number of sons, (d) women's education, (e) wealth quintile, (f) religion, (g) caste, (h) place of residence in India, NFHS-4 (2015-2016) Source: Author's calculation based on NFHS-4 (2015-2016) 


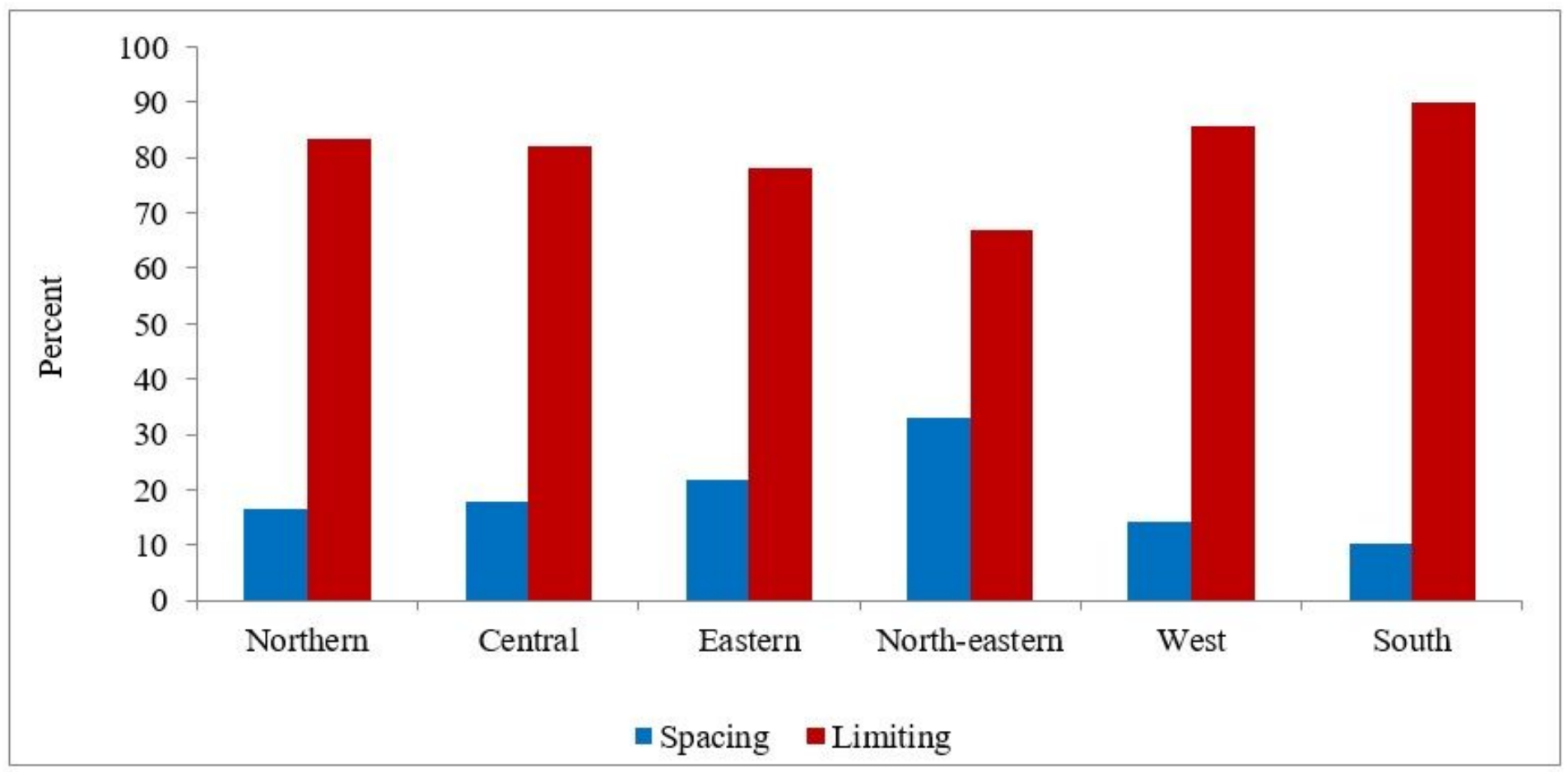

\section{Figure 3}

Regional patterns of existing demand for spacing among the currently married women aged 15-49 years, those who had demand for family planning in India, 2015-16 Source: Author's calculation based on NFHS-4 (2015-2016) 


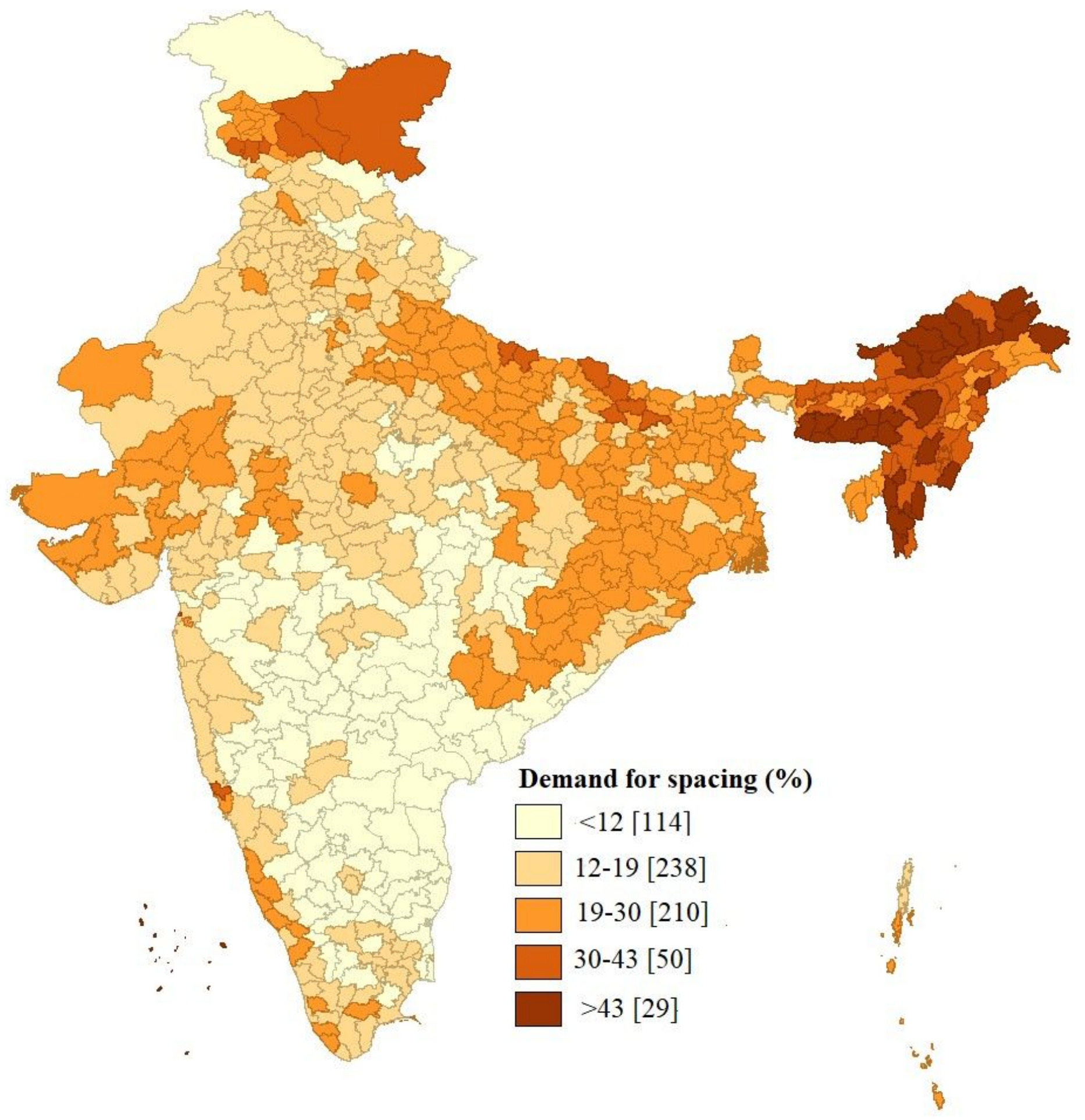

\section{Figure 4}

District level patterns of existing demand for spacing among the currently married women aged 15-49 years, those who had demand for family planning in India, 2015-16 Source: Author's calculation based on NFHS-4 (2015-2016) 


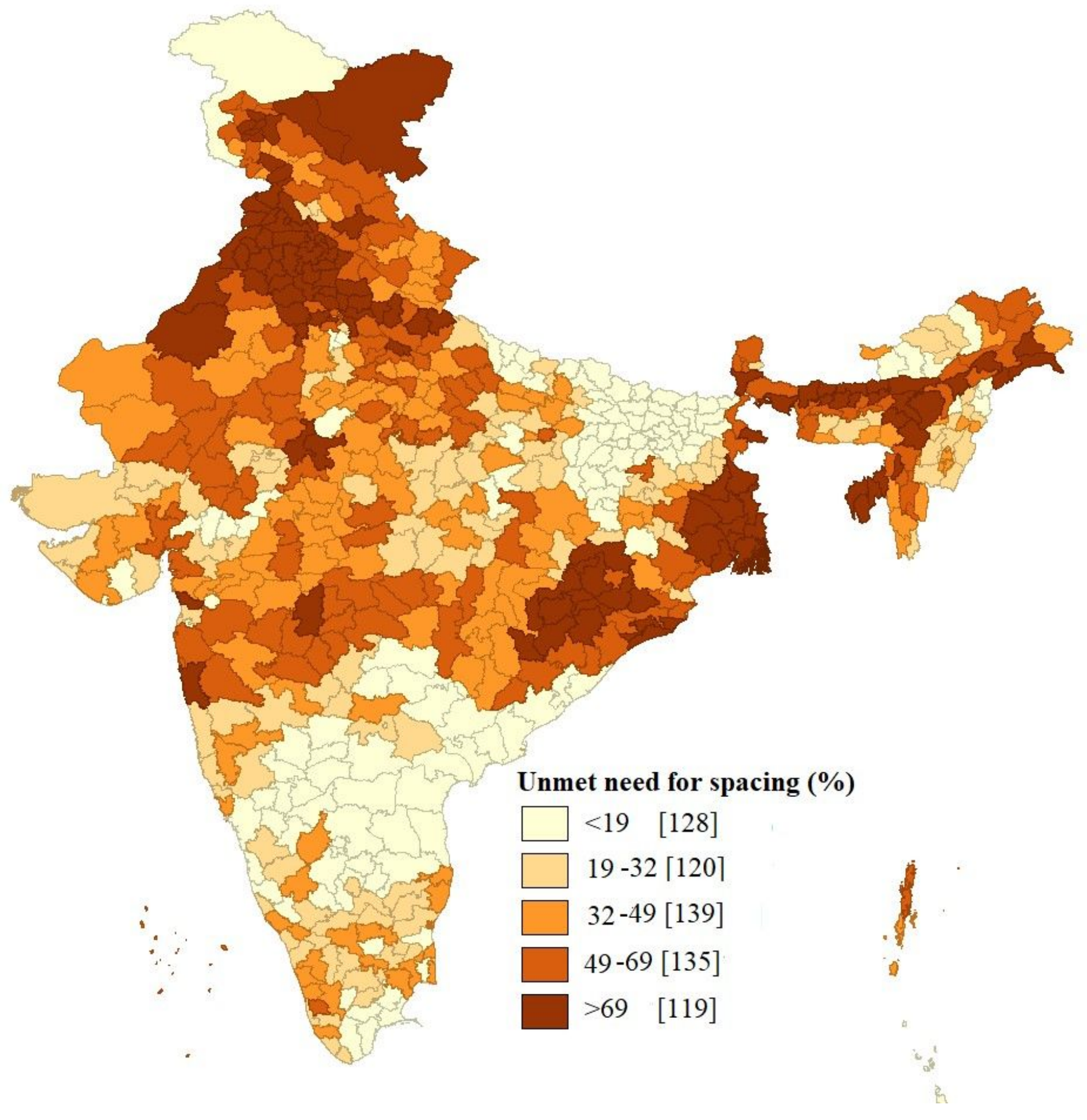

Figure 5

District level patterns of prevalence of unmet need for spacing among the currently married women aged 15-49 years, those who had demand for spacing in India, 2015-16 Source: Author's calculation based on NFHS-4 (2015-2016) 